\title{
Influence of School Culture and Classroom Environment in Improving Soft Skills amongst Secondary Schoolers
}

\author{
Abdul Razaq Ahmad \\ Prof. Dr., The National University of Malaysia, Selangor, Malaysia, razaq@ukm.edu.my \\ Fong Peng Chew \\ Dr., University of Malaya, Kuala Lumpur, Malaysia, fpchew@um.edu.my \\ Hutkemri Zulnaidi \\ Dr., University of Malaya, Kuala Lumpur, Malaysia, hutkemri@um.edu.my \\ Kiagus Muhammad Sobri \\ Prof. Dr., University of Sriwijaya, Sumatera Selatan, Indonesia, sobriunsri@gmail.com \\ Alfitri \\ Prof.Dr.,University of Sriwijaya, Sumatera Selatan, Indonesia,_al_fitri2002@yahoo.com
}

$\mid$

This study aimed to determine the influence of support from the school culture and classroom environment in improving soft skills amongst students. Moreover, the study explored different soft skills, school culture and classroom environments based on gender and type of schools. This study used a quantitative approach by using surveys to gather information. A total of 400 students from three different types of schools were chosen using random sampling. The three types of schools were National Secondary Schools, Religious Secondary Schools, and Technical and Vocational Secondary Schools around Selangor and Federal Territory of Kuala Lumpur. Data were analysed using SPSS 22.0 and AMOS 18. Results confirmed the distinctions of the school culture and classroom environments with the soft skills based on the gender and type of schools. SEM analysis corroborated that the school culture and classroom environment contributed to the development of soft skills. Therefore, schools should come up with programs and approaches to improve the soft skills amongst the students to be proficient in various fields in parallel with the rapid growth of the world.

Keywords: classroom environment, school culture, soft skills, secondary schools, type of schools

Citation: Ahmad, A. R., Chew, F. P., Zulnaidi, H., Sobri, K. M., \& Alfitri. (2019). Influence of School Culture and Classroom Environment in Improving Soft Skills amongst Secondary Schoolers. International Journal of Instruction, 12(2), 259-274. https://doi.org/10.29333/iji.2019.12217a 


\section{INTRODUCTION}

People nowadays are living in an information-oriented condition full of new information and knowledge. Competition is serious amongst people, and the country is in need of high-quality manpower to face the upcoming challenges. Such situation requires a solid foundation to produce future generations with calibre, skills and safety from social problems. Therefore, the increased complexity of today's work environment has created the need for soft skills, such as teamwork, communication, leadership and problem solving, more salient than ever (Ritter, Small, Mortimer \& Doll, 2018). As such, soft skills have been proven to predict outcomes in school and in life (Mulcahy-Dunn, King \& Lee, 2018).

Education plays an important role in the development of human capital with a strong identity, competence, nobility, knowledge and skills to fill the needs of developed countries. Various efforts have been taken by the Ministry of Education (MOE) and the Ministry of Higher Education Malaysia (MOHE) to improve the education system in Malaysia. Learning methods were introduced to ensure that the education systems achieve the educational goals and to produce individuals who are well-balanced spiritually, emotionally and physically (Ali, Islamiah Rosli, Sujadi, Usodo, \& Adie Perdana, 2017). Individuals should be able to think critically and creatively, solve problems, create new opportunities, have resilience and cope with the changes of the global world.

To be competitive, Malaysia should have an education system that can produce students who are ready to work. Students' soft skills must be developed to prepare them for the workplace. The significance of this problem has led many Malaysian researchers to conduct studies to understand the root of the problem and provide practical solutions. Researchers have looked at the problem from different perspectives. Most of the studies, some of which are briefly introduced below, have focused on the employers expressing their needs and demands, whereas some have looked at the problem from the perspective of universities and academics (David \& Saeipoo, 2018). Only a few studies focused on Malaysian secondary students' needs or understanding of soft skills. The current research fills this gap by encompassing some government secondary schools in Malaysia.

\section{PROBLEM STATEMENT}

\section{Soft Skills}

Soft skills are known by various names: generic skills, human skills, non-technical skills, essential skills and employability skills. Soft skills are the essential skills and added values to the system of teaching in schools, apart from the core curriculum; it also can be the additional curriculum. According to Cimatti (2016), soft skills are used to indicate personal transversal competencies, such as social aptitudes, language and communication capability, friendliness and ability to work in a team and other personality traits that characterise relationships between people. Soft skills are developed through natural processes such as growth, maturation and aging (Seetha, 
2013). In a nutshell, soft skills refer to personality traits, social attraction, language skills, personal values, attitudes, awareness and sensitivity or an optimistic attitude.

The Malaysian Education Blueprint for the period of 2013-2025 (2013) has highlighted the importance of the development aspects of student outcomes as an indicator to create students who can meet the challenges of the new millennium, the prospect of jobs and competitiveness at the global level. Six aspects of student outcomes emerge, namely, knowledge and thinking skills, national identity, ethics, spirituality, leadership skills and bilingual skills. The six aspects have been highlighted to be the needs and demands of the industry. Thus, the success of the students cannot rely solely on academic excellence or purely intellectual ability.

According to Zhou (2017), soft skills are widely considered key elements that contribute to the sustainable development of nations and the well-being of individuals. Heckman and Kautz (2012) corroborated that soft skills predict success in life, that they produce such success and that the programs that enhance soft skills have an important place in an effective portfolio of the employers. The desired human resources in the working world are those who have various abilities and skills (multi-skills) (Suchitra, 2013). Mastery of skills such as communication, problem solving, decision making, leadership, teamwork and other soft skills are fundamental considerations in selecting an employee. In fact, many companies worldwide nowadays put a greater weight on soft skills over technical skills, while others consider them equally important or complementary to each other (Young \& Chapman, 2011; Pradeep \& Dinakar, 2018). Soft skills are important as they complement the process of applying knowledge. Hence, the development of the students must be accompanied by the development of the soft skills in various aspects in schools. Therefore, a review of the role of education in developing the human capital is essential.

Considerable research has been done at the university level (Supitcha, Cholticha, Sittipong, \& Wannalak, 2014, Gibert, Tozer \& Westoby, 2017, David \& Saeipoo, 2018), such as teamwork skills; entrepreneurial skills and application of soft skills amongst teachers, coaches and others. However, limited studies have been carried out in relation to the lack of soft skills at the school level. Nevertheless, programs and activities that take place in schools and classrooms that contain the elements of soft skills either directly or indirectly still emerge. Therefore, the soft skills should be studied to see the aspects dominated by the students. Apart from the schools, the role of family and friends must also be consdiered because it may affect the behaviours and practices of the students. Therefore, a study in secondary schools must be carried out to determine the factors that affect the practices of soft skills.

\section{School Culture and Classroom Environments}

The school environment can be defined as a set of internal characteristics that distinguishes one school from another and that influences the behavior of staff members and students (Hoy \& Miskel, 2013). Character building starts from the school. The school is a formal institution that catalyses the field of education in the society. The school provides a suitable and conducive climate for the translation of character building through the practices of the knowledge and behaviours amongst students. The 
classroom is a place where the process of delivering knowledge and human development happens. In the classroom, the teacher plays a vital role in implementing the values of good character through expertise, competence and skills using appropriate strategies and methods of teaching and learning process (T\&L). Through good interaction between teachers and students, the T\&L process can take place effectively.

Sarjou, Soltani, Kalbasi and Mahmoudi (2012) affirmed that the school culture refers to the values, principles, traditions and habits formed in school, developed in the school in the long-term and and gripped and believed by all people in schools to encourage the emergence of attitudes and behaviour of the school community. Erwin (2018) emphasised that school culture may foster or draw on student resilience to support their successful completion of high school. In sum, the school culture refers to a system of values, beliefs and norms accepted and implemented together with the full awareness of the natural behaviour that is shaped by the environment (De Vries, Bakker-Pieper \& Oostenveld, 2010). According to Sarjou, Soltani, Kalbasi and Mahmoudi (2012), school culture is the soul and the strength of the school that develop and adapt to the environment. Factors supporting the cultural environment of the school and classroom practices also affect students' soft skills. Ecology Theory by Bronfenbrenner was contended to have relevance to this study. Bronfenbrenner (1977) validated that an individual is not a passive recipient of experiences in the environment, but someone who helps develop the environment or atmosphere.

Therefore, this study aimed to determine whether the teachers play a role in providing guidance in terms of interaction with classmates, giving analytical tasks and problems, promoting teamwork, encouraging students to think in a creative manner and associating learning with current issues. In addition, the promotion of the use of information and communication technology (ICT) by giving an assignment to find additional resources must be done to improve the management skills of ICT. Good communication and interaction between teachers and students and amongst peers is also important to apply learning in the classroom.

Furthermore, this study aimed to review the support of the environmental sustainability of the cultural aspects of school and classroom towards the soft skills acquisition related to leadership, communication, thinking skills, information technology management and interpersonal and collaboration skills amongst students in secondary schools. The study also intended to investigate the different constructs of soft skills based on the type of schools. Figure 1 exhibits the conceptual framework of the study. 


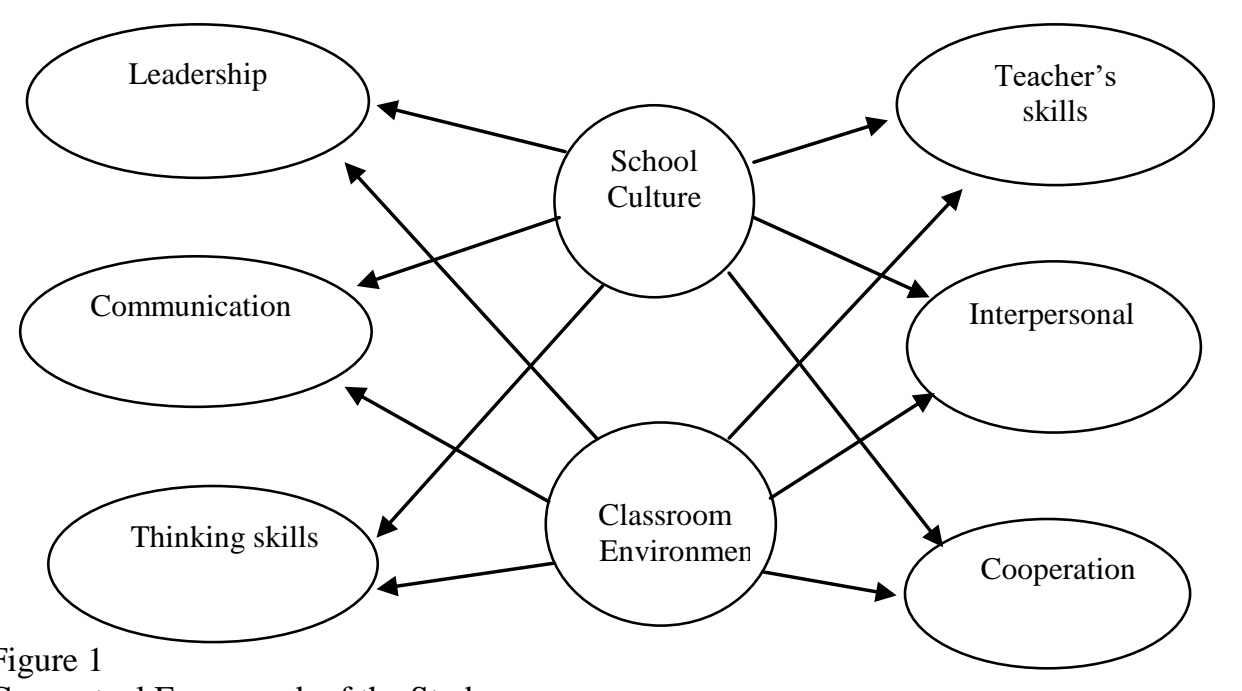

Conceptual Framework of the Study

\section{METHOD}

This study involved 400 respondents, composed of students from six schools of three different types, namely, National Secondary Schools (NSS) $(n=200)$, Religious Secondary Schools $(\mathrm{RSS})(\mathrm{n}=100)$ and Technical and Vocational Secondary Schools (T\&VSS) $(n=100)$ in the state of Selangor and the Federal Territory of Kuala Lumpur. Simple random sampling was used to determine the sample of the study. Patton (1990) mentioned no rules to determine the sample size. However, a big sample for research survey using a questionnaire is better. In this study, three categories of school were selected. The number of National Secondary Schools was more than that of Religious Secondary Schools and Technical and Vocational Secondary Schools. Therefore, the sample for National Secondary Schools is larger than that for others. Sudman (1976) asserted that a minimum of 100 elements were required for each major group or subgroup in the sample.

\section{Measure}

Environment Support. Environmental support instrument was developed by researchers and has been reviewed by experts for validity. After getting the approval from two experts and improving the questionnaire based on the recommendations of experts, a total of 21 items were determined to measure environmental support. Two aspects in environmental support emerge, namely, cultural environment of the school and the classroom environment support. For the cultural environment support of the school, nine items were available to measure school culture, which include the providing a range of activities, counselling facilities, providing ICT training and encouraging students to interact with teachers. For the classroom environment support, 12 items were available, which include providing guidance, giving assignments, encouraging communication and mutual respect and associating learning with current issues. 
Soft Skills. Soft skills instruments have been developed by using a five-point Likert scale ( 1 as strongly disagree to 5 as strongly agree). Construction items for this study were adapted from the Soft Skills Development Model for Malaysian Higher Institutions of Education by Umar (2006) and National Education Blueprint 2013-2025 (2013). After improving the instrument based on the recommendations of two experts, 50 items of soft skills emerged, which comprised six aspects, namely, leadership (nine items), communication (eight items), thinking (eight items), transformational technology management (six items), interpersonal skills (eight items) and working together (10 items).

\section{Procedure of Study}

Initially, this study has been approved by the Ministry of Education Malaysia followed by distribution of questionnaires by the researchers to three categories of schools (i.e, National Secondary Schools, Religious Secondary Schools, and Technical and Vocational Secondary Schools) around the Selangor and Federal Territory of Kuala Lumpur. The pilot study was performed amongst 100 students in the City of Kajang, Malaysia. Results were processed using SPSS version 22.0 to measure the reliability of each item based on Cronbach's alpha value. The results of the pilot study verified that the items of the questionnaire were highly reliable with scores between 0.73 and 0.94 . A total of 400 questionnaires have been distributed for the actual study and received returns in the same amount. Returned data were reviewed, and no sample was dropped because the information obtained was complete. Subsequently, the researchers began to enter the data into SPSS 22.0 software and perform data analysis to answer the research questions. The analysis started with coding, screening, cleaning, normality testing and inference testing. A parametric test was also used in this study, and the assumption of parametric test was achieved (normality, homogeneity and sample size). MANOVA analysis was used to determine the differences of school culture and classroom support amongst students based on the type of schools. Structural equation model (SEM) analysis was used to determine the support contributed by the school culture and classrooms on soft skills. The present study used an index matching the size commonly used as a benchmark in determining the fitness matching model, such as root meansquare error of approximation (RMSEA), the comparative fit index (CFI) and normed chi-square ( $\chi 2$ / df) (Hair et al., 2014).

\section{Confirmatory Factor Analysis (CFA)}

The relationship between each variable was between .42 and .96 . In the instrument, support from school and classroom culture of each item had a loading factor of more than .5. The fitness indices and normed chi-square with the level of significance claimed that the chi-square was a good model and significant (Kline, 2005) with chi-square / $\mathrm{df}=$ $4.48, \mathrm{CFI}=.95, \mathrm{GFI}=.94, \mathrm{TLI}=.93$ and RMSEA $=.07$, thereby suggesting that the resulting model was good. Hence, each item could be used to measure each of the variables being studied to achieve the objectives and goals of the study. 


\section{FINDINGS}

\section{Different School Culture and Classroom Support amongst Students Based on Type of} Schools

MANOVA analysis was carried out to determine the differences of school culture and classroom support amongst students based on the type of schools. Data collected on school culture and classroom support were of normal distribution with skewness (.68) and kurtosis (.89) value in between -3 and +3 . Box's $M$ test showed no significant difference in the variance-covariance significance amongst the dependent variables for all independent variables with the Box's $\mathrm{M}=79,213$ and $p=.004$ ( $\mathrm{p}>.001$ ). This scenario confirmed that the variance-covariance of the dependent variable was homogenous across the independent variables. Therefore, MANOVA analysis could be performed to determine the differences in the school environment support amongst the students based on the type of schools. Significant differences emerged in the school environment support amongst the students based on the type of schools and the Wilks' = $.614, \mathrm{~F}(1,397)=.00(p<.01)$. Table 1 exhibits the differences amongt every aspect of support from school culture and classroom environment amongst students based on the type of schools identified using MANOVA analysis.

Table 1 shows significant differences in terms of the school environment support amongst students based on different types of schools with $\mathrm{F}=65.591$ and $p=.00$ ( $p$ $<.01)$. Students of T\&VSS $(\mathrm{M}=3.12, S D=0.38)$ had higher support provided by the school cultural environment compared with students in RSS $(\mathrm{M}=2.81, S D=.64)$ and NSS $(\mathrm{M}=2.62, S D=.76)$. The aspect of classroom support also showed a significant difference with the value of $\mathrm{F}=104.770$ and $p=.00(p<.01)$. Students in T\&VSS $(\mathrm{M}=$ 3.94, $S D=.30)$ received higher classroom support than the students in RSS $(\mathrm{M}=3.81$, $S D=.45)$ and NSS $(\mathrm{M}=3.68, S D=.51)$.

Table 1

Manova Test of Difference of the School Culture and Classroom Environment amongst Students based on Type of Schools

\begin{tabular}{llllllllll}
\hline $\begin{array}{l}\text { School } \\
\text { environment }\end{array}$ & $\begin{array}{l}\text { Type of } \\
\text { schools }\end{array}$ & N & Min & $S D$ & $\begin{array}{l}\text { Sum of } \\
\text { squares }\end{array}$ & $d f$ & $\begin{array}{c}\text { Total } \\
\text { power of } \\
\text { two }\end{array}$ & F & $p$ \\
\hline School & NSS & 200 & 2.62 & .76 & 55.744 & 2 & 27.872 & 65.591 & .00 \\
Culture & RSS & 100 & 2.81 & .64 & & & & & \\
& T\&VSS & 100 & 3.12 & .38 & & & & & \\
Classroom & NSS & 200 & 3.68 & .51 & 42.340 & 2 & 21.170 & 104.770 & .00 \\
& RSS & 100 & 3.81 & .45 & & & & & \\
& T\&VSS & 100 & 3.94 & .30 & & & & & \\
\hline
\end{tabular}

To see in detail the difference in the support provided by school culture and classroom environment amongst students based on type of schools, the Scheffe post hoc test was conducted. 
Table 2

Scheffe Post Hoc Test on the Difference of the School Culture and Classroom Environment amongst Students based on Type of Schools

\begin{tabular}{llccc}
\hline Variable & School & NSS & RSS & T\&VSS \\
\hline School Culture & NSS & - & $-.19^{*}$ & $-.50^{*}$ \\
& RSS & $.19^{*}$ & - & $-.31^{*}$ \\
& T\&VSS & $.50^{*}$ & $.31^{*}$ & - \\
Classroom & NSS & - &.$-13^{*}$ & $-.26^{*}$ \\
Environment & RSS & $.13^{*}$ & - & $-.13^{*}$ \\
& T\&VSS & $.26^{*}$ & $.13^{*}$ & - \\
\hline
\end{tabular}

*Significant level at .05

Table 2 shows that significant differences emerged in the support provided by the school culture and classroom environment in NSS, RSS and T\&VSS. T\&VSS students gained the highest degrees compared with students in NSS and RSS. The analysis also showed that students in NSS scored the lowest value of environmental sustainability.

\section{Differences of Soft Skills Acquisition amongst Students based on Type of Schools}

MANOVA analysis was conducted to see the differences of soft skill acquisition amongst students based on the type of schools. The data collected for soft skills acquisition were of normal distribution with skewness (.98) and kurtosis (1.52) value in between -3 and +3 . Box's $M$ test showed no significant difference in the variancecovariance significance amongst the dependent variable for all levels of independent variables with Box's $\mathrm{M}=232817$ and $p=.05(p>.01)$. This scenario deduced that the variance-covariance of dependent variable was homogenous across the independent variables. Therefore, the analysis could be performed to find out the differences in soft skills acquisition amongst students based on the type of schools. Significant differences emerged in soft skills acquired by students based on the type of schools and the Wilks' = $.577, \mathrm{~F}(397)=.00(p<.01)$. The difference was proven to be significant in every aspect of soft skills, including leadership, communication, thinking skills, information technology management skills and interpersonal and collaboration skills amongst students based on the type of schools using MANOVA test. Table 3 shows significant differences in terms of soft skills in leadership $[F=107.96$ and $p=.00(p<.01)]$, communication $[F=105.374$ and $p=.00(p<.01)]$, thinking skills $[F=73.853$ and $p=$ $.00(p<.01)]$, information technology management $[F=43.440$ and $p=.00(p<.05)]$, interpersonal $[F=41.492$ and $p=.00(p<.05)]$ and cooperation $[F=69.046$ and $p=$ $.00(p<.05)]$ based on the type of schools. Overall, students in T\&VSS had teamed up higher than the students in RSS and NSS.

Table 3

Manova Test of Difference of Soft Skills Acquisition amongst Students Based on Type of Schools

\begin{tabular}{|c|c|c|c|c|c|c|c|c|c|}
\hline Soft skills & $\begin{array}{l}\text { Types of } \\
\text { schools }\end{array}$ & $\mathrm{N}$ & $\mathrm{M}$ & $S D$ & $\begin{array}{l}\text { Type III } \\
\text { sum of } \\
\text { squares }\end{array}$ & $d f$ & $\begin{array}{l}\text { Sum of } \\
\text { square }\end{array}$ & $\mathrm{F}$ & $p$ \\
\hline Leadership & NSS & 200 & 3.40 & .59 & 74.754 & 2 & 37.377 & 107.963 & .00 \\
\hline
\end{tabular}




\begin{tabular}{llllllllll}
\hline \multirow{3}{*}{ Communication } & T\&VSS & 100 & 4.45 & .40 & & & & & \\
& NSS & 200 & 3.32 & .62 & 82.476 & 2 & 41.238 & 105.374 & .00 \\
& RSS & 100 & 3.68 & .80 & & & & & \\
Thinking & T\&VSS & 100 & 4.43 & .41 & & & & & \\
& NSS & 200 & 3.58 & .56 & 45.898 & 2 & 22.949 & 73.853 & .00 \\
& RSS & 100 & 3.79 & .65 & & & & & \\
Management of & T\&VSS & 100 & 4.41 & .44 & & & & & \\
informational & NSS & 200 & 3.80 & .70 & 33.751 & 2 & 16.875 & 43.440 & .00 \\
technology & RSS & 100 & 4.01 & .62 & & & & & \\
Interpersonal & T\&VSS & 100 & 4.51 & .45 & & & & & \\
& NSS & 200 & 3.76 & .55 & 25.153 & 2 & 12.577 & 41.492 & .00 \\
& RSS & 100 & 3.93 & .67 & & & & & \\
Cooperation & T\&VSS & 100 & 4.37 & .41 & & & & & \\
& NSS & 200 & 2.80 & .3 & 39.841 & 2 & 19.920 & 69.046 & .00 \\
& RSS & 100 & 3.05 & .64 & & & & & \\
& T\&VSS & 100 & 3.15 & .42 & & & & & \\
\hline
\end{tabular}

The Scheffe post hoc test was carried out to determine in detail the differences in soft skill acquisition, including leadership, communication, thinking skills, information technology management skills, interpersonal and collaboration skills amongst students based on the type of schools. Table 7 exhibits its results.

Scheffe post hoc tests as a whole corroborated that students from T\&VSS acquired the soft skills of leadership, communication, thinking skills, information technology management skills, interpersonal and collaboration skills than NSS and RSS students and that NSS students gained the lowest value of human skills.

Table 4

Post Hoc Scheffe of Differences of Soft Skill Acquisition Based on Type of Schools

\begin{tabular}{|c|c|c|c|c|}
\hline Variable & School & NSS & RSS & T\&VSS \\
\hline \multirow[t]{3}{*}{ Leadership } & NSS & - & $-.23 *$ & $-1.05^{*}$ \\
\hline & RSS & $.23 *$ & - & $-.82 *$ \\
\hline & T\&VSS & $1.05 *$ & $.82 *$ & - \\
\hline \multirow[t]{3}{*}{ Communication } & NSS & - & $-.36^{*}$ & $-.11 *$ \\
\hline & RSS & $.36 *$ & - & $-.75^{*}$ \\
\hline & T\&VSS & $1.11^{*}$ & $.75^{*}$ & - \\
\hline \multirow[t]{3}{*}{ Thinking } & NSS & - & $-.20 *$ & $-.83^{*}$ \\
\hline & RSS & $20 *$ & - & $-.62^{*}$ \\
\hline & T\&VSS & $.83^{*}$ & $.62 *$ & - \\
\hline Management & NSS & - & $-.21 *$ & $-.71^{*}$ \\
\hline Informational & RSS & $.21 *$ & - & $-.50 *$ \\
\hline technology & T\&VSS & $.71 *$ & $.50 *$ & - \\
\hline \multirow[t]{3}{*}{ Interpersonal } & NSS & - & $-.17 *$ & $-.61 *$ \\
\hline & RSS & $.17 *$ & - & $-.44 *$ \\
\hline & T\&VSS & $.61 *$ & $.44 *$ & - \\
\hline \multirow[t]{3}{*}{ Cooperation } & NSS & - &.$-25^{*}$ & $-.35^{*}$ \\
\hline & RSS & $.25 *$ & - & $-.10^{*}$ \\
\hline & T\&VSS & $.35^{*}$ & $.10 *$ & - \\
\hline
\end{tabular}

*Significant level at .05 
The analysis of the structural equation model showed the values of the index was mismatched between data models with sample sizes of Chi Square/ $\mathrm{df}=4.74$, the Root Mean Square Error of Approximation (RMSEA) $=.07$, the Fitness Index $(\mathrm{GFI})=.94$, Comparative Fit Index (CFI) $=.95$ and Fit Tucker-Lewis index (TLI) $=.95$. In addition, the factor loading for each item measured the involvement and support from teachers, peers and parents to be more than .5. Overall, the results of the assessment affirmed that a good correspondence emerged between the model and the data in this study. Further assessment was carried out for each coefficient.

The path coefficient showed significant contribution between the variables mentioned. Support of school culture $(\beta=.14, \mathrm{p}<.01)$ and classroom environment $(\beta=.99, \mathrm{p}<$ $.01)$ were significant predictors of leadership skills. Support of school culture $(\beta=.15, \mathrm{p}$ $<.01)$ and classroom environment $(\beta=.99, \mathrm{p}<.01)$ were significant predictors of communication skills. School culture $(\beta=.90, \mathrm{p}<.01)$ and classrooms environment $(\beta=$ $.45, \mathrm{p}<.01)$ were significant predictors of thinking skills. Support of school culture $(\beta=$ $.20, \mathrm{p}<.01)$ and classrooms environment $(\beta=.15, \mathrm{p}<.01)$ were significant predictors of technology management skills. School culture $(\beta=.90, p<.01)$ and classrooms environment $(\beta=.43, p<.01)$ were significant predictors of interpersonal skills, whereas the school culture $(\beta=.28, p<.01)$ and classrooms environment $(\beta=.96, p<$ $.01)$ were significant predictors of working skills.

Figure 2 illustrates the contributions of the support of school culture and classroom environment on the soft skill acquisition in the aspects of leadership, communication, thinking skills, information technology, management skills, interpersonal and collaborative skills.

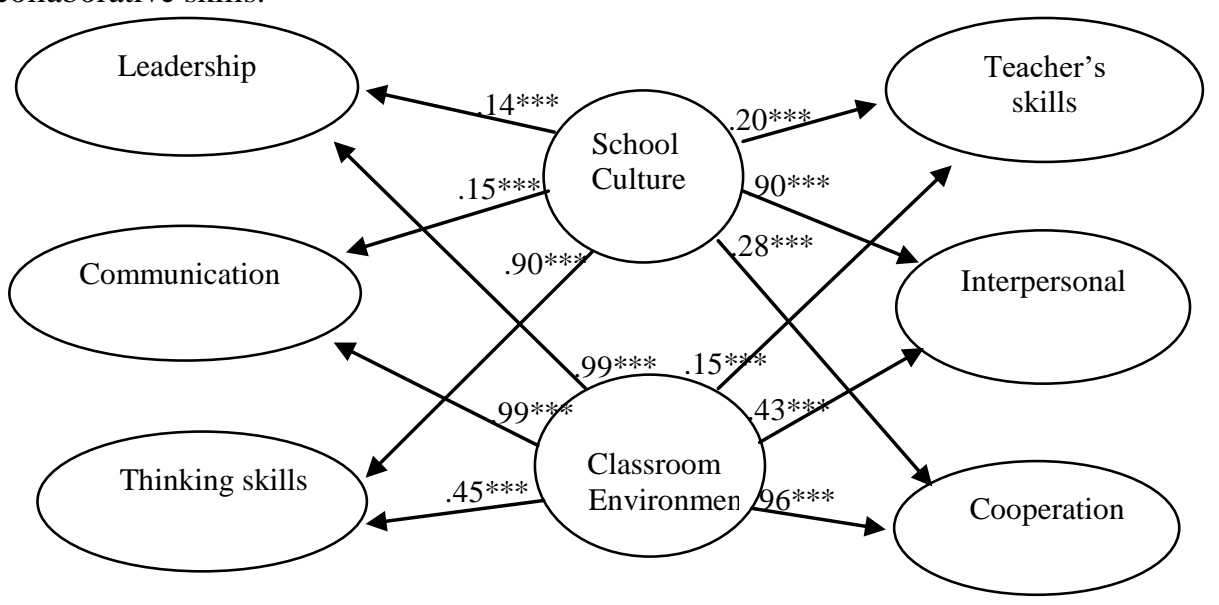

Figure 2

Contribution of the support of school culture and classroom environment on the soft skills (***significant level at .001). 


\section{DISCUSSION}

The results showed significant differences in the support of school culture amongst students based on type of schools. The study claimed that students in T\&VSS gained higher support of school culture than the students in RSS and NSS. Support from the classroom environment amongst students based on type of schools also showed a significant difference. The study showed that T\&VSS students had higher support of classroom environment compared with the students from RSS and NSS. These findings were supported by the study by Machumu, Zhu and Sesabo (2016) who asserted that soft skills are applied at a higher level in T\&VSS when students are in the classroom, workshop, and when students attend extra-curricular activities. Support of the students in T\&VSS is inseparable from the support of teachers. Teachers are to be regarded as guides and guards determining the success of learning (Kitchen \& Raynor, 2013). Therefore, teachers are expected to develop their personal pedagogical ability. Pedagogical ability of teachers can be achieved by attending few training sessions, seminars and talks. Teachers who have high ability will be able to form more creative, critical and innovative thinking skills amongst the students.

Findings proved that significant differences of soft skills in leadership, communication, thinking skills, information technology management, interpersonal and collaboration skills emerged amongst students based on the type of schools. The study validated that T\&VSS students had higher soft skills than the students in RSS and NSS. One reason is that teachers at T\&VSS emphasise more the practice of soft skills in schools. This finding was consistent with the research carried out by British Council led by Chan, Goh and Prest (2015) who verified that soft skills are applied in technical secondary schools at a higher level. This activity was done through students' involvement in class, student workshops and co-curricular activities. Their involvement had developed their teamwork, cooperation and interaction skills. Furthermore, Tarricone and Luca (2012) inferred that teamwork is the most important element and should be mastered by all students to achieve excellence, glory and distinction. At school, students will be in touch with their teachers and friends. These relationships lead to psychological impact. Therefore, relationship with others can be met by creating a feeling of security amongst them and thus, encouraging the students to get involved actively with the school's activities.

Results confirmed that a significant contribution of the support of school culture and classroom environment on the students emerged. The findings also asserted that the classroom environment has a strong impact on leadership, communication and collaboration skills and that the school culture provided a strong impact on thinking and interpersonal skills, which showed that support from the school environment is important in applying the soft skills amongst the students because the school is the main institution where students gain knowledge and useful experiences through activities. This statement is similar with the opinion of Hasan, Abdul Kadir and Asimiran (2013) who proved that the school environment helps to increase the students' involvement in extracurricular activities. Through participation in extracurricular activities, soft skills amongst students will be enhanced indirectly because students will be exposed to 
communicate with teachers and peers, leadership skills, working skills and others. In this study, T\&VSS students had higher support from the school environment. This could be attributed to T\&VSS students having the tendency towards two soft skills of lifelong learning and teamwork skills. This statement supported the findings of Hasan, Abdul Kadir and Asimiran (2013), and Konsky, Miller and Jones (2016) stating that the technical stream students tend to master the soft skills of lifelong learning and teamwork skills.

The establishment of school culture reflected deep trust and confidence of school staff in developing students' characters through their views, attitudes and behaviours in schools. The environmental impact of a strong school culture on the interpersonal skills of the students is manifested in schools where teachers and the schools provide an opportunity for parents, peers and the physical environment in the social activities of students. Supportive parents, peers, school and a safe environment provided positive impact on students' involvement in physical activity in school or leisure activities. Efficacy, adolescents' experience and peer emotional support also had impact on the treatment of their physical activity. Such statement is supported by Vet, Ridder and Wit (2011) who claimed that the interpersonal support from parents, peers, the school and the physical environment was important for the involvement of young people in social activities. Therefore, intervention programs are urgently needed to enhance youth participation in leisure time as a whole.

The results of this study posed issues that must be considered by some parties involved in the field of education. The school culture is lacking in providing an impact on leadership, communication, information technology management and cooperation skills amongst the students. Similarly, the classroom environment showed a low impact on information technology management skills. Leadership skills are needed by students to strive to get jobs and maintain their relationship with society. Therefore, leadership skills should be taken into account at an early stage in the process of schooling. This statements is supported by Fan (2010) who claimed that the students' leadership skills can be applied to the field of employment and relations with the public. In addition, the school culture provided less impact on communication amongst the students. The interaction between students and teachers and students with students was a characteristic of being able to produce effective leadership. De Vries, Bakker-Pieper and Oostenveld (2010) emphasised the importance of communication for leadership. Their study showed the relationship between leaders' communication styles and charismatic leadership. Clokie and Fourie's research (2016) proved that the employers' value for communication competencies was high, and specific communication skills that reflect course content is required in an industry when recruiting new graduates. Therefore, the issue becomes important and should be taken into account in improving the soft skills amongst the students.

The study found that supports from both the cultural environment of schools and classrooms provided less impact on information technology management skills. This might be due to the lack of students' ability to use technology as an access to sites, social platforms, portals, movies, blogs and so on. Facilities supporting the use of information 
technology is sufficient to be used in teaching and learning. However, management skills are not getting better today. Such statement supported the view of Konsky, Miller and Jones (2016) who validated that the capacity for managing information technology allowed students to acquire knowledge and information related to their learning better. The teacher is a factor in managing information technology in school effectively. Teachers are considered as an important source of guidance to lead students to achieve academic excellence. In this context, teachers are the source of inspiration for students to motivate them to continue to strive for success in life (Wonglorsaichona, Wongwanich \& Wiratchaib, 2014). Therefore, the role of the teacher is required to control the students' ability in information technology management, and ultimately affect the students' future achievement and success.

This study contended that soft skills amongst the secondary school' students had increased. They are in need of continuous support from teachers in order to improve their soft skills. Support should be provided through self-learning in the classroom and instilling soft skills in the process of teaching and learning in every subject. This effort will facilitate the enhancement of soft skills, especially in relation to communication, information technology management skills and so on. This idea was similar to the opinion of Wonglorsaichona, Wongwanich and Wiratchaib (2014) who indicated that students are hoping to acquire soft skills from their teachers who care for them. The preparation of a good learning environment and clear aims will improve students' academic achievement and their engagement in school. Emphasizing good relations with teachers is important so that students' commitment to learning are always high. Therefore, locally designed blended learning should be relevant to the environment for both students and teachers (Machumu, Zhu and Sesabo, 2016).

The school must also create a culture that can be implemented and will affect the behaviours of the students towards soft skills. The environment and culture of the school should create a space for more innovations and competitiveness by organizing various events and activities and by encouraging students' participation in these activities. Corner speeches, quiz competitions, lectures and other activities must be carried out continuously and periodically to improve students' soft skills. In addition, the school must strive to create a culture and environment that is student-friendly to be easily absorbed into soft skills amongst students directly and indirectly. The Ministry of Education (MOE) must make changes in the school curriculum to include soft skills in the subjects taught in school. In addition, the MOE must also organise more training and courses for teachers so that the application of soft skills amongst students is successfully implemented. Therefore, teachers should be given continuous exposure through inservice training in order to be more effective in teaching soft skills to students. This study also recommends that future research could be improved in terms of theory, respondents, data collection methods and use of additional or more appropriate variables.

\section{CONCLUSIONS}

Schools play an important role in instilling and improving soft skills amongst the students. Soft skills are very important to enable students to venture into the job market 
after graduating from their schools as the present line of work is very particular on the soft skills such as leadership, communication, thinking skills, and information technology management, interpersonal and collaboration skills. This study showed distinctions between the school culture and classroom environment in relation with the students' soft skills based on the gender and type of schools. SEM analysis also showed that there were significant contributions of the school culture and classroom environment towards the development of the soft skills. This study implies that the support from the school culture and classroom environment influences the improvement of soft skills amongst secondary school students. Therefore, all parties including the MOE, the school administrators and teachers should cooperate to produce skilled human capital who are capable of entering the workplace in the future. Further research can be conducted on the curriculum for soft skills development based on the gender and type of school by emphasizing the important element of school culture and classroom environment.

\section{REFERENCES}

Ali, A., Islamiah Rosli, D., Sujadi, I., Usodo, B., \& Adie Perdana, F. (2017). Mastering the soft skills in the implementation of work-based learning among community college students. Journal of Physics: Conference Series, 795(1), 1-11.

Brancato G., Macchia S., Murgia M., Signore M., Simeoni, G., Blanke K., Körner T., Nimmergut, A., Lima, P., Paulino, R., \& Hoffmeyer-Zlotnik J. H. P. (2006). Handbook of Recommended Practices for Questionnaire Development and Testing in the European Statistical System. Europian Commision Grant.

Bronfenbrenner, U. (1977). Toward an experimental psychology of human development. American Psychologist, 32, 513-532.

Byrne, B. M. (2012). Structural Equation Modelling with Mplus: Basic Concepts, Applications, and Programming (Multivariate Applications). $\left(2^{\text {nd }}\right.$ Ed.). New York: Taylor \& Francis Group.

Chan, J., Goh, J., \& Prest, K. (2015). Soft Skills, Hard Challenges: Understanding the Nature of China's Skills Gap. British Council.

Cimatti, B. (2016). Definition, Development, Assessment of Soft Skills and Their Role for The Quality of Organizations and Enterprises. International Journal for Quality Research 10(1) 97-130.

David, M. K., \& Saeipoo, N, (2018). Integrating Soft Skills into Courses in Malaysian Public Universities (Undergraduates' Perception). International Research Journal, 8(1). Retreived from: http://researth.iars.info/index.php/curie/article/view/83/70

De Vries R. E., Bakker-Pieper A., \& Oostenveld, W. (2010). Leadership = Communication? The relations of leaders' communication styles with leadership styles, knowledge sharing and leadership outcomes. Journal of Business and Psychology, 25(3), 367-380. 
Erwin, A. S. (2018). Creating a Strong School Culture to Prevent High School Dropouts. Doctorate of Philosophy, Dissertation. University of Portland.

Fan, M. (2010). Systema and Leadership: One Tool to Enhance Foundational Leadership Competencies. The Engineering Leadership Review, 1(1), 45-56.

George, D., \& Mallery, P. (2015). IBM SPSS Statistics 21 Step by Step: A Simple Guide and Reference. (13 ${ }^{\text {th }}$ Ed.). Boston: Allyn \& Bacon.

Gibert, A., Tozer, W. C., \& Westoby, M. (2017). Teamwork, Soft Skills, and Research Training. Trends Ecology and Evolution, 32(2), 81-84.

Hair, J. F., Black, W. C., Babin, B. J., Anderson, R. E., \& Tatham, R. L. (2014). Multivariate Data Analysis. ( $7^{\text {th }}$ Ed.). New Jersey: Prentice Hall.

Hasan, M. F., Abdul Kadir. S., \& Asimiran, S. (2013). Relation of school environment with the involvement of students in co-curricular activities in secondary schools [Malay Language]. Journal of Education in Malaysia, 38 (2): 1-9.

Heckman, J. J., \& Kautz, T. (2012). Hard evidence on soft skills. Labour Economic. 19(4): 451-464.

Hoy, W. K., \& Miskel, C. G. (2013). Educational Administration: Theory, Research, and Practice. ( $9^{\text {th }}$ Ed.). New York: Random House.

Kitchen, J., \& Raynor, M. (2013). Indigenizing Teacher Education: An Action Research Project. Canadian Journal of Action Research, 14(3), 40-58.

Konsky, B. R., Miller, C., \& Jones, A. (2016). The Skills Framework for the Information Age: Engaging Stakeholders in Curriculum Design. Journal of Information Systems Education, 27(1), 37-50.

Machumu, H. J., Zhu, C., \& Sesabo, J. K. (2016). Blended learning in the vocational education and training system in Tanzania: Understanding vocational educators' perceptions. International Journal of Multicultural and Multireligious Understanding, $3(2), 30-45$.

Marcial, D. E. (2012). Investigating soft skills among information technology managers in higher education institutions in the Philippines. Education, Research and Innovation, 47, 7-11.

Mulcahy-Dunn, A., King, S. J., \& Lee, E. N. (2018). The relationship between grit, selfcontrol, and early grade reading: a trial measuring soft skills in rural Tanzania. Educational Psychology, 38(8), 997-1009.

Pallant, J. (2013). A Step by Step Guide to Data Analysis Using SPSS for Windows. $\left(5^{\text {th }}\right.$ Ed.). Buckingham, Philadelphia: Open University Press.

Patton, M. Q. (1990). Qualitative Evaluation and Research Method. Newbury Park: CA Sage. 
Pradeep, M. P., \& Dinakar, G. (2018). Employee Perception on Skill Development Programs at Information Technology Companies in Bangalore- An Empirical Study. International Journal of Social Science Research, 88-99.

Ritter, B. A., Small, E. E., Mortimer, J. W., \& Doll, J. L. (2018). Designing Management Curriculum for Workplace Readiness: Developing Students' Soft Skills. Journal of Management Education, 42(1), 80-103.

Sarjou A. A., Soltani A., Kalbasi A., \& Mahmoudi, S. (2012). A study of Iranian students' attitude towards science and technology, school science and environment based on the ROSE Project. Journal of Studies in Education, 2(1), 90-103.

Schumacker, R. E., \& Lomax, R. G. (2015). A Beginner's Guide to Structural Equation Modeling ( $4^{\text {th }}$ Ed.). New Jersey: Lawrence Erlbaum Associates.

Seetha, C. (2013). Are soft skills important in the workplace? - A preliminary investigation in Malaysia. International Journal of Academic Research in Business and Social Sciences, 4(4), 44-56.

Suchitra P. (2013). Building Multi-Skills Based Talent Management. IOSR Journal of Business and Management, 15(2), 1-3.

Sudman S. (1976). Applied Sampling. New York: Academic Press.

Supitcha C., Cholticha N., Sittipong S., \& Wannalak L. (2014). Industrial sectors' need of cooperative students with desired characteristics. International Journal of Innovation, Management and Technology, 70(11), 53-58.

Tarricone, P., \& Luca, J. (2002). Successful teamwork: A case study. In Research and Development in Higher Education: Quality Conversations Vol. 25 (pp.640-646). Tony Herrington.

Umar, R. S. (2006). Soft Skills Development module for Malaysian Higher Education Institutions. Serdang: Putra University of Malaysia Press.

Vet, E., Ridder, D. T. D., \& Wit, J. B. F. (2011). Environmental correlates of physical activity and dietary behaviours among young people: a systematic review of reviews. Obesity Review, 12(5), e130-e142.

Wonglorsaichona, B., Wongwanich, S., \& Wiratchaib, N. (2014). The Influence of Students School Engagement on Learning Achievement: A Structural Equation Modeling Analysis. Procedia - Social and Behavioral Sciences, 116, 1748-1755.

Young, J., \& Chapman, E. (2011). Generic competency frameworks: A brief historical overview. Education Research and Perspectives, 37(1). 1-24.

Zhou, K. (2017). Non-cognitive skills: Potential candidates for global measurement. European Journal of Education, 52(4), 487-497. 